\title{
Health Effects of Ozone on Respiratory Diseases
}

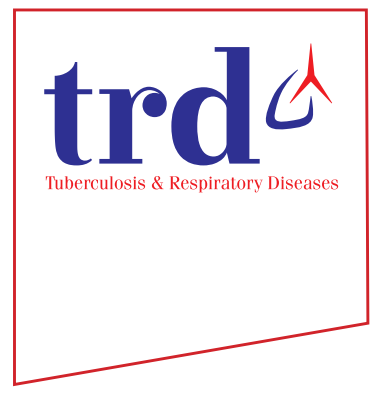

\author{
Sun-Young Kim, Ph.D. ${ }^{1}$ (D) , Esther Kim, M.S. ${ }^{2}$ and Woo Jin Kim, M.D. ${ }^{2}$ (i) \\ ${ }^{1}$ Department of Cancer Control and Population Health, Graduate School of Cancer Science and Policy, National Cancer \\ Center, Goyang, ${ }^{2}$ Department of Internal Medicine and Environmental Health Center, Kangwon National University School of \\ Medicine, Chuncheon, Republic of Korea
}

Ozone is known to cause bronchial inflammation and airway hyper-responsiveness via oxidative injury and inflammation. While other ambient air pollutants such as particulate matter (PM) and nitrogen dioxide showed decreasing trends in mean annual concentrations, ozone concentrations have not declined recently in most countries across the world. Short-term exposure to high concentrations of ozone has been associated with increased mortality and cardiovascular and respiratory morbidity in many regions of the world. However, the long-term effects of ozone have been less investigated than the short-term exposure due to the difficulty in modeling ozone exposure and linking between individual exposures and health outcome data. A recently developed model of ozone exposure enabled the investigation of long-term ozone effects on health outcomes. Recent findings suggested that long-term exposure to ozone was associated with an increased risk of cardiovascular and respiratory mortality. Longitudinal studies using large cohorts also revealed that long-term exposure to ozone was associated with a greater decline in lung function and the progression of emphysema. The development of long-term standards for ozone as well as PM should be considered to protect the respiratory health of the general population and people with chronic respiratory diseases.

Keywords: Asthma; Chronic Obstructive Pulmonary Disease; Interstitial Pulmonary Fibrosis; Ozone

\section{Introduction}

According to global burden of disease attributed to ozone exposure, 254,000 global excess mortality were reported in $2015^{1}$. This is ten times less than that attributable to particulate matter $2.5\left(\mathrm{PM}_{2.5}\right)$, which was 4.2 million death in 2015 .

\footnotetext{
Address for correspondence: Woo Jin Kim, M.D.

Department of Internal Medicine and Environmental Health Center, Kangwon National University School of Medicine, 156 Baengnyeong-ro, Chuncheon 24289, Republic of Korea

Phone: 82-33-258-9364, Fax: 82-33-255-6567

E-mail:pulmo2@kangwon.ac.kr

Received: Nov. 30, 2020

Revised: Dec. 1, 2020

Accepted: Dec. 1, 2020

Published online: Dec. 1, 2020

(c) It is identical to the Creative Commons Attribution Non-Commercial License (http://creativecommons.org/licenses/by-nc/4.0/).
}

Mortality due to ozone exposure may seem trivial compared to the number of deaths associated with $\mathrm{PM}_{2.5}$, but it is more widely distributed worldwide ${ }^{1}$. As the aging population grows, air pollution has become a bigger problem in the Asia-Pacific region than before ${ }^{2}$. Due to constant efforts to mitigate air pollution in many countries, air quality has improved. Nonetheless, even though annual average concentrations of fine particulate matter and nitrogen dioxide have decreased since 2000, annual ozone levels continue to increase ${ }^{3}$. On an individual level, it is recommended that susceptible individuals avoid outings on days when ozone level is high. While smoking cessation is mainly a consequence of personal efforts ${ }^{4}$, mitigation of ambient air pollution also depends on national policy and regulation. In Korea, 8-hour average ozone standard is currently set to be 60 parts per billion (ppb), but there is no standard on long-term standards such as mean annual concentrations. This paper emphasizes the continual need to analyze the existing standards to improve and protect population health. 


\section{Short-Term Exposure to Ozone and Respiratory Diseases}

\section{Overview}

There is ample evidence that supports the association of short-term ozone exposure and respiratory health outcomes in terms of mortality and exacerbations. To evaluate shortterm effects of ozone exposure, time-series or case-crossover study designs that aim to assess whether there is an increase in mortality or hospital admission or visits to emergency department (ED) soon after ozone level increases are widely used.

\section{Mortality}

Many studies have demonstrated that short-term ozone exposure increased total mortality, respiratory and cardiovascular mortality globally ${ }^{5-7}$. Short-term warm-season ozone exposure was associated with increased risk of mortality in the U.S. Medicare population data ${ }^{8}$. This study also highlighted that this risk occurred at levels below current national air quality standards. The association between short-term exposure and mortality was also reported in East Asia ${ }^{9}$. This study also showed that ambient ozone was associated with an increased risk of mortality in a relatively low range of levels in Korea, Japan, and Taiwan.

When meteorological factors were taken into consideration, lung cancer mortality risk increased during the warm season, especially in men and elderly patients ${ }^{10}$. Considering that lung cancer occurs predominantly in the elderly, close attention should be given and specific management should be considered $^{11}$. During the warm/summer season, for example, elderly patients should try to stay inside during daytime in order to prevent ozone exposure as much as possible. Such recommendation may lead to a decrease in physical activity although evidence shows the benefits of physical activity even in polluted areas ${ }^{12}$. Therefore, potential risks and benefits should be well-evaluated in the future guidelines.

\section{Respiratory outcomes}

A recent systemic review and meta-analysis indicated that short-term ozone exposure was associated with an increased risk of chronic obstructive pulmonary disease (COPD) hospitalizations $^{13}$. Furthermore, recent study reported that ozone level was associated with COPD incidence ${ }^{14}$. A higher number of hospitalizations and ED visits reflect poor prognosis of COPD patients and place an enormous economic burden not only on the patients, but also on national medical costs ${ }^{15}$.

Interstitial pulmonary fibrosis (IPF) is another chronic respiratory disease that should be paid attention to as it is the most common and severe form idiopathic interstitial pneu- monia $^{16}$. While several papers reported that traffic-related air pollution is associated with poor outcomes including mortality and hospital admission in IPF patients ${ }^{17-19}$, effects of ozone should yet to be investigated in depth.

Ozone exposure was known to increase asthma exacerbations $^{20}$. According to recent report, short-term exposure of ambient ozone increased ED visits due to asthma in children throughout the Pittsburg area at lag day 1 (odds ratio, 1.12; $95 \%$ confidence interval $[\mathrm{CI}], 1.03-1.22 ; \mathrm{p}<0.05)^{21}$.

Of interest, when age-specific effects of $\mathrm{PM}_{2.5}$ and ozone on ED visits due to respiratory diseases including acute respiratory infection, asthma, and COPD were evaluated, children were found to be more susceptible to $\mathrm{PM}_{2.5}$ while the elders were more vulnerable to ozone ${ }^{22}$. This study suggested that elderly subjects may be more susceptible to ozone due to physiological and structural change.

\section{Mechanism of injury}

Ozone exposure triggers bronchial inflammation and hyper-responsiveness; respiratory tract oxidative stress leads to allergic sensitization, morphological changes of the tract, and impaired host defense $\mathrm{e}^{23}$. The increased airway responsiveness then causes airway obstruction and decrements in lung function. Furthermore, sensory nerves in respiratory tract as well as local reflex responses are activated, diminishing inspiratory capacity and incurring pain on inspiration.

\section{Association with Long-Term Exposure to Ozone in Epidemiological Studies}

\section{Overview}

Epidemiological evidence of the association of long-term exposure to ozone is remarkably limited compared to the association of short-term exposure. Although many toxicological studies and controlled exposure studies consistently suggested the association, there have been relatively fewer epidemiological studies that showed the association particularly for incidence ${ }^{24,25}$. This limited evidence is also different from other pollutants. While large cohort studies in North America, Europe, and Asia consistently reported the association of long-term exposure to particulate matter and nitrogen dioxide with mortality, lung cancer, and cardiovascular and respiratory diseases ${ }^{26}$, findings for ozone remained inconsistent. Based on these inconsistent findings, the comprehensive review report of the U.S. Environmental Protection Agency (U.S. EPA) focusing on ozone concluded that the causal association of long-term exposure to ozone is only suggestive ${ }^{24}$. The association of long-term ozone was relatively stronger in a few respiratory outcomes including incidence of asthma than other major endpoints such as mortality, cardiovascular 
diseases, and lung cancer. A few recent studies have expanded the outcomes of interest and found the associations with subclinical cardiovascular and respiratory endpoints. These studies adopted advanced exposure prediction approaches to estimate individual-level exposure to ozone. One of the recent advances in epidemiological studies of assessing the impact of long-term air pollution is the development of exposure prediction approaches to overcome unavailability of individual exposure measurements ${ }^{27}$. Cohort studies of air pollution have developed simple to advanced exposure prediction models to estimate individual-level long-term concentrations at people's homes and work. As there have been relatively fewer cohort studies for ozone than for other pollutants, ozone prediction models were recently adopted and contributed to finding of new evidence of the association. Whereas long-term exposure to air pollution was generally assessed as average concentrations of 24-hour means over one to multiple years, most studies of ozone used warm-season averages of 1 or 8-hour maximum to represent large production of ozone derived by chemical reaction with sunlight and high temperature.

\section{Mortality}

Although some cohort studies in the United States and Canada reported the modest association of long-term exposure to ozone and non-accidental mortality ${ }^{28.31}$, other cohort studies in the United States, Europe, and Asia reported no association $^{32-34}$. A large cohort study in the United States including 60 million Medicare beneficiaries over 65 years old in the continental United States for 2000-2012 estimated individuallevel warm-season exposure to ozone based on zipcode-level addresses using a previously validated exposure prediction model $^{31}$. They found that a $10 \mathrm{ppb}$ increase in ozone was associated with a $1 \%$ (hazard ratio [HR], 1.01; 95\% CI, 1.01-1.01) increase in non-accidental mortality. Canadian studies of 2-3 million people in the Canadian Census Health and Environment Cohort (CanCHEC) followed for more than 10 years estimated warm-season postal-code residential concentrations using an exposure prediction model, and found $8 \%$ (HR, 1.08; 95\% CI, 1.02-1.24) and 7\% (HR, 1.07; 95\% CI, 1.06-1.08) increases in non-accidental mortality ${ }^{28,30}$. Estimated risk for respiratory mortality tended to be stronger in the American Cancer Society (ACS) cohort in the United States ${ }^{29,35}$, but other cohort studies in Canada, England, and France reported no association ${ }^{32,33,36}$. The first ACS study used 450 thousand people living in metropolitan areas of the United States with 18 years of follow-up period, and assigned city-wide averages of regulatory monitoring data for $1997-2000^{35}$. While ozone was not associated with total mortality, they found that a 10 ppb increase in ozone was associated with a $4 \%$ increase in respiratory mortality (HR, 1.04; 95\% CI, 1.01-1.07). A follow-up study that expanded the population and focused on specific respiratory mortality found $10 \%$ (HR, 1.10; 95\% CI, 1.03-1.18) and 14\% (HR, 1.14; 95\% CI, 1.08-1.21) increases in pneumonia and COPD mortality, respectively ${ }^{29}$. Studies of the association with cardiovascular mortality largely reported inconsistent findings.

\section{Respiratory and cardiovascular outcomes}

Evidence of long-term ozone and respiratory health was mostly obtained from asthma incidence in children. The Children's Health Study (CHS) that followed up approximately 4,000 children in 12 communities in California, USA since 1993 found that children living in the communities with decreased ozone concentration over almost 20 years from 1-year concentration at baseline showed decreased asthma incidence compared to those living in the communities with increased ozone ${ }^{37}$. In the early CHS data with 5 -year follow-up, children in the communities with high ozone concentration showed higher incidence when exercised more compared to those exercised less ${ }^{38}$. A Canadian study based on the Quebec Integrated Chronic Disease Surveillance System cohort with 2-year follow-up also showed the association with asthma onset. Using 1 million children and their summertime ozone concentrations estimated at zip-code addresses at birth, a 10 ppb increase in ozone was associated with $38 \%$ increase in asthma onset (HR, 1.38; 95\% CI, 1.34-1.42) ${ }^{39}$. Other studies investigated the associations with lung function, lung development, respiratory infection, and allergic sensitization, but findings were mostly inconsistent ${ }^{40-42}$. Recently, the MultiEthnic study of Atherosclerosis and Air Pollution (MEAS Air) developed a spatio-temporal prediction model to estimate individual-level long-term ozone concentrations of about 6,000 health adults over 45 years old and living in six major US cities. Using percent emphysema obtained by cardiac computed tomography scan, this study found the association with greater increase in percent emphysema at baseline $(0.43$ for $10 \mathrm{ppb}$ increase in ozone; $95 \% \mathrm{CI}, 0.10-0.80$ ) as well as during follow-up $(0.60 ; 95 \% \text { CI, } 0.27-0.93)^{3}$. Long-term ozone was associated with lung function, emphysema severity, respiratory symptoms, and exacerbations in a heavy smoker cohort with or without $\mathrm{COPD}^{43}$. Findings of cardiovascular outcomes have been sparse. A few recent cohort studies focused on subclinical atherosclerosis assessed by carotid intima media thickness (CIMT) from ultrasound imaging in college students in the Testing Responses on Youth (TROY) study and healthy adults of MESA Air. The TROY computed different exposures according to different periods based on regulatory monitoring data and residential addresses, and found the associations using elementary school exposure $(10.1 \mu \mathrm{m}$; 95\% CI, 1.8-18.5) but not for early childhood and lifetime exposures ${ }^{44}$. In the MESA Air, baseline exposure was associated with a greater increase in CIMT over 10 years $(18.7 \mu \mathrm{m} ; 95 \% \mathrm{CI}, 4.7-32.3)^{45}$. 


\section{Conclusions}

There are evidences for adverse health effects of short-term ambient ozone exposure. We should consider such adverse events occurred under the current standards, and a suspected increase in ozone level due to climate change when making future environmental policy. There has been emerging research interest in the health effect of long-term exposure to ozone, as recent findings suggested the associations with respiratory and cardiovascular outcomes accompanied by advanced exposure assessment mostly in large U.S. cohort studies. However, findings were still limited and inconsistent. In particular, there has been only one study that investigated the association with long-term ambient ozone in other regions than North America and Europe. This South Korean study reported a negative association with non-accidental mortality ${ }^{34}$. Methodological limitations such as no adjustment for other pollutants and potential measurement error resulting from limited monitoring data were also indicated as challenges to assess the valid association. Future studies need to apply local exposure prediction models to assess accurate individual exposure and to investigate expanded health endpoints in welldesigned cohort studies focusing on diverse population.

\section{Authors' Contributions}

Conceptualization: Kim WJ. Writing - original draft preparation: Kim SY, Kim E. Writing - review and editing: Kim WJ. Approval of final manuscript: all authors.

\section{Conflicts of Interest}

No potential conflict of interest relevant to this article was reported.

\section{Funding}

No funding to declare.

\section{References}

1. Cohen AJ, Brauer M, Burnett R, Anderson HR, Frostad J, Estep K, et al. Estimates and 25-year trends of the global burden of disease attributable to ambient air pollution: an analysis of data from the Global Burden of Diseases Study 2015. Lancet 2017;389:1907-18.

2. North CM, Rice MB, Ferkol T, Gozal D, Hui C, Jung SH, et al. Air pollution in the Asia-Pacific region: a Joint Asian Pacific Society of Respirology/American Thoracic Society perspec- tive (republication). Respirology 2019;24:484-91.

3. Wang M, Aaron CP, Madrigano J, Hoffman EA, Angelini E, Yang J, et al. Association between long-term exposure to ambient air pollution and change in quantitatively assessed emphysema and lung function. JAMA 2019;322:546-56.

4. Chun EM. Smoking cessation strategies targeting specific populations. Tuberc Respir Dis 2019;82:1-5.

5. Bell ML, McDermott A, Zeger SL, Samet JM, Dominici F. Ozone and short-term mortality in 95 US urban communities, 1987-2000. JAMA 2004;292:2372-8.

6. Gryparis A, Forsberg B, Katsouyanni K, Analitis A, Touloumi G, Schwartz J, et al. Acute effects of ozone on mortality from the "air pollution and health: a European approach" project. Am J Respir Crit Care Med 2004;170:1080-7.

7. Bell ML, Dominici F, Samet JM. A meta-analysis of time-series studies of ozone and mortality with comparison to the national morbidity, mortality, and air pollution study. Epidemiology 2005;16:436-45.

8. Di Q, Dai L, Wang Y, Zanobetti A, Choirat C, Schwartz JD, et al. Association of short-term exposure to air pollution with mortality in older adults. JAMA 2017;318:2446-56.

9. Huang WH, Chen BY, Kim H, Honda Y, Guo YL. Significant effects of exposure to relatively low level ozone on daily mortality in 17 cities from three Eastern Asian countries. Environ Res 2019;168:80-4.

10. Wang N, Mengersen K, Tong S, Kimlin M, Zhou M, Wang L, et al. Short-term association between ambient air pollution and lung cancer mortality. Environ Res 2019;179:108748.

11. Kim HC, Jung CY, Cho DG, Jeon JH, Lee JE, Ahn JS, et al. Clinical characteristics and prognostic factors of lung cancer in Korea: a pilot study of data from the Korean nationwide lung cancer registry. Tuberc Respir Dis 2019;82:118-25.

12. Han Y, Heo Y, Hong Y, Kwon SO, Kim WJ. Correlation between physical activity and lung function in dusty areas: results from the chronic obstructive pulmonary disease in dusty areas (CODA) cohort. Tuberc Respir Dis 2019;82:311-8.

13. Gao H, Wang K, W WA, Zhao W, Xia ZL. A systematic review and meta-analysis of short-term ambient ozone exposure and COPD hospitalizations. Int J Environ Res Public Health 2020;17:2130.

14. Shin S, Bai L, Burnett RT, Kwong JC, Hystad P, van Donkelaar $\mathrm{A}$, et al. Air pollution as a risk factor for incident COPD and asthma: 15-year population-based cohort study. Am J Respir Crit Care Med 2020 Nov 4 [Epub]. https://doi.org/10.1164/ rccm.201909-1744OC.

15. Kim C, Kim Y, Yang DW, Rhee CK, Kim SK, Hwang YI, et al. Direct and indirect costs of chronic obstructive pulmonary disease in Korea. Tuberc Respir Dis 2019;82:27-34.

16. Lee SH, Yeo Y, Kim TH, Lee HL, Lee JH, Park YB, et al. Korean guidelines for diagnosis and management of interstitial lung diseases: part 2. Idiopathic pulmonary fibrosis. Tuberc Respir Dis 2019;82:102-17.

17. Dales R, Blanco-Vidal C, Cakmak S. The association between 
air pollution and hospitalization of patients with idiopathic pulmonary fibrosis in Chile: a daily time series analysis. Chest 2020;158:630-6.

18. Yoon HY, Kim SY, Kim OJ, Song JW. Nitrogen dioxide increases the risk of mortality in idiopathic pulmonary fibrosis. Eur Respir J 2020 Nov 12 [Epub]. https://doi.org/10.1183/ 13993003.01877-2020.

19. Harari S, Raghu G, Caminati A, Cruciani M, Franchini M, Mannucci P. Fibrotic interstitial lung diseases and air pollution: a systematic literature review. Eur Respir Rev 2020;29: 200093.

20. Li X, Chen Q, Zheng X, Li Y, Han M, Liu T, et al. Effects of ambient ozone concentrations with different averaging times on asthma exacerbations: a meta-analysis. Sci Total Environ 2019;691:549-61.

21. Byrwa-Hill BM, Venkat A, Presto AA, Rager JR, Gentile D, Talbott E. Lagged association of ambient outdoor air pollutants with asthma-related emergency department visits within the Pittsburgh region. Int J Environ Res Public Health 2020;17:8619.

22. Strosnider HM, Chang HH, Darrow LA, Liu Y, Vaidyanathan A, Strickland MJ. Age-specific associations of ozone and fine particulate matter with respiratory emergency department visits in the United States. Am J Respir Crit Care Med 2019; 199:882-90.

23. Bontinck A, Maes T, Joos G. Asthma and air pollution: recent insights in pathogenesis and clinical implications. Curr Opin Pulm Med 2020;26:10-9.

24. U.S. Environmental Protection Agency. Integrated science assessment (ISA) for oxides of nitrogen: health criteria (final report, Jan 2016) [Internet]. Washington, DC: U.S. Environmental Protection Agency; 2016 [cited 2020 Dec 2]. Available from: https://cfpub.epa.gov/ncea/isa/recordisplay.cfm?deid=310879.

25. European Environment Agency. Air pollution due to ozone: health impacts and effects of climate change [Internet]. Luxembourg: Publications Office of the European Union; 2015 [cited 2020 Dec 2]. Available from: https://www.eea.europa.eu/dataand-maps/indicators/air-pollution-byozone-2/assessment.

26. U.S. EPA. Integrated science assessment (ISA) for particulate matter (final report, Dec 2019) [Internet]. Washington, DC: U.S. Environmental Protection Agency; 2019 [cited 2020 Dec 2]. Available from: https://cfpub.epa.gov/ncea/isa/recordisplay. cfm?deid $=347534$.

27. Hoek G. Methods for assessing long-term exposures to outdoor air pollutants. Curr Environ Health Rep 2017;4:450-62.

28. Cakmak S, Hebbern C, Pinault L, Lavigne E, Vanos J, Crouse DL, et al. Associations between long-term $\operatorname{PM}(2.5)$ and ozone exposure and mortality in the Canadian Census Health and Environment Cohort (CANCHEC), by spatial synoptic classification zone. Environ Int 2018;111:200-11.

29. Turner MC, Jerrett M, Pope CA 3rd, Krewski D, Gapstur SM, Diver WR, et al. Long-term ozone exposure and mortality in a large prospective study. Am J Respir Crit Care Med
2016;193:1134-42.

30. Weichenthal S, Pinault LL, Burnett RT. Impact of oxidant gases on the relationship between outdoor fine particulate air pollution and nonaccidental, cardiovascular, and respiratory mortality. Sci Rep 2017;7:16401.

31. Di Q, Wang Y, Zanobetti A, Wang Y, Koutrakis P, Choirat C, et al. Air pollution and mortality in the medicare population. $\mathrm{N}$ Engl J Med 2017;376:2513-22.

32. Bentayeb M, Wagner V, Stempfelet M, Zins M, Goldberg M, Pascal M, et al. Association between long-term exposure to air pollution and mortality in France: a 25-year follow-up study. Environ Int 2015;85:5-14.

33. Carey IM, Atkinson RW, Kent AJ, van Staa T, Cook DG, Anderson HR. Mortality associations with long-term exposure to outdoor air pollution in a national English cohort. Am J Respir Crit Care Med 2013;187:1226-33.

34. Kim H, Kim J, Kim S, Kang SH, Kim HJ, Kim H, et al. Cardiovascular effects of long-term exposure to air pollution: a population-based study with 900845 person-years of followup. J Am Heart Assoc 2017;6:e007170.

35. Jerrett M, Burnett RT, Pope CA 3rd, Ito K, Thurston G, Krewski D, et al. Long-term ozone exposure and mortality. N Engl J Med 2009;360:1085-95.

36. Crouse DL, Peters PA, Hystad P, Brook JR, van Donkelaar A, Martin RV, et al. Ambient PM2.5, $\mathrm{O}_{3}$, and $\mathrm{NO}_{2}$ exposures and associations with mortality over 16 years of follow-up in the Canadian Census Health and Environment Cohort (CanCHEC). Environ Health Perspect 2015;123:1180-6.

37. Garcia E, Berhane KT, Islam T, McConnell R, Urman R, Chen $\mathrm{Z}$, et al. Association of changes in air quality with incident asthma in children in California, 1993-2014. JAMA 2019;321: 1906-15.

38. McConnell R, Berhane K, Gilliland F, London SJ, Islam T, Gauderman WJ, et al. Asthma in exercising children exposed to ozone: a cohort study. Lancet 2002;359:386-91.

39. Tétreault LF, Doucet M, Gamache P, Fournier M, Brand A, Kosatsky T, et al. Childhood exposure to ambient air pollutants and the onset of asthma: an administrative cohort study in Québec. Environ Health Perspect 2016;124:1276-82.

40. Gauderman WJ, Urman R, Avol E, Berhane K, McConnell R, Rappaport E, et al. Association of improved air quality with lung development in children. N Engl J Med 2015;372:905-13.

41. Smith GS, Van Den Eeden SK, Garcia C, Shan J, Baxter R, Herring $\mathrm{AH}$, et al. Air pollution and pulmonary tuberculosis: a nested case-control study among members of a Northern California Health Plan. Environ Health Perspect 2016;124:761-8.

42. Weir CH, Yeatts KB, Sarnat JA, Vizuete W, Salo PM, Jaramillo R, et al. Nitrogen dioxide and allergic sensitization in the 20052006 National Health and Nutrition Examination Survey. Respir Med 2013;107:1763-72.

43. Paulin LM, Gassett AJ, Alexis NE, Kirwa K, Kanner RE, Peters $\mathrm{S}$, et al. Association of long-term ambient ozone exposure with respiratory morbidity in smokers. JAMA Intern Med 
2020;180:106-15.

44. Breton CV, Wang X, Mack WJ, Berhane K, Lopez M, Islam TS, et al. Childhood air pollutant exposure and carotid artery intima-media thickness in young adults. Circulation 2012;126:1614-20.
45. Wang M, Sampson PD, Sheppard LE, Stein JH, Vedal S, Kaufman JD. Long-term exposure to ambient ozone and progression of subclinical arterial disease: the multi-ethnic study of atherosclerosis and air pollution. Environ Health Perspect 2019;127:57001 